\title{
Prognostic value of protein tyrosine kinase 6 (PTK6) for long-term survival of breast cancer patients
}

\author{
M Aubele*, , AK Walch', N Ludyga', H Braselmann ${ }^{2}$, MJ Atkinson ${ }^{3,4}$, B Luber $^{5}$, G Auer $^{6}$, S Tapio $^{3}$, T Cooke $^{7}$ and \\ JMS Bartlett ${ }^{8}$
}

'Institute of Pathology, Helmholtz Centre Munich, German Research Centre for Environmental Health, Neuherberg D-85764, Germany; ${ }^{2}$ Institute of Molecular Radiation Biology, Helmholtz Centre Munich, German Research Centre for Environmental Health, Neuherberg D-85764, Germany; ${ }^{3}$ Institute of Radiation Biology, Helmholtz Centre Munich, German Research Centre for Environmental Health, Neuherberg D-85764, Germany; ${ }^{4}$ Klinik für Strahlentherapie, Technische Universität München, Ismaninger Strasse 22, München 81675, Germany; ${ }^{5}$ Institut für Pathologie, Technische Universität München, Trogerstr. 18, München 81675, Germany; ${ }^{6}$ Department of Oncology and Pathology, Karolinska Institute and Hospital, Stockholm S-17176, Sweden; ${ }^{7}$ University Department of Surgery, Glasgow Royal Infirmary, Queen Elizabeth Building, 10 Alexandra Parade, Glasgow G3I 2ER, UK;

${ }^{8}$ Endocrine Cancer Group, Cancer Research Centre, Western General Hospital, Crewe Road South, Edinburgh EH4 2XR, UK

The cytoplasmic tyrosine kinase PTK6 (BRK) shows elevated expression in approximately two-thirds of primary breast tumours, and is implicated in EGF receptor-dependent signalling and epithelial tumorigenesis. Using immunohistochemistry, we performed a retrospective study on 426 archival breast cancer samples from patients with long-term follow-up and compared the protein expression levels of PTK6, the HER receptors, Sam68 (a substrate of PTK6), and signalling proteins including MAP kinase (MAPK), phosphorylated MAPK (P-MAPK), and PTEN. We show that PTK6 expression is of significant prognostic value in the outcome of breast carcinomas. In multivariate analysis, the disease-free survival of patients of $\geqslant 240$ months was directly associated with the protein expression level of PTK6 $(P \leqslant 0.001)$, but was also inversely associated with nodal status $(P \leqslant 0.001)$ and tumour size $(P \leqslant 0.01)$. PTK6 expression in tumour tissue significantly correlated $(P \leqslant 0.05)$ with the expression of PTEN, MAPK, P-MAPK, and Sam68. To investigate whether these correlations may be due to molecular interactions between PTK6 and these proteins, we used protein extracts from the T47D cell line for immunoprecipitation and western blot analysis. By this, interactions could be demonstrated between PTK6 and MAPK, P-MAPK, HER2/neu, HER3, HER4, PTEN, and Sam68. On the basis of these results, we suggest that PTK6 may serve as a future target for the development of novel treatments in breast cancer.

British Journal of Cancer (2008) 99, 1089- 1095. doi:I0.1038/sj.bjc.6604660 www.bjcancer.com

Published online 9 September 2008

(c) 2008 Cancer Research UK

Keywords: PTK6 (BRK); breast cancer; prognosis; MAPK; Sam68; PTEN

The cytoplasmic protein tyrosine kinase PTK6 (BRK, breast tumour kinase) was originally cloned from a human metastatic breast tumour (Mitchell et al, 1994). PTK6 was shown to be overexpressed in two-thirds of breast carcinomas (Mitchell et al, 1994; Barker et al, 1997; Llor et al, 1999; Born et al, 2005; Aubele et al, 2007; Ostrander et al, 2007), and expression is elevated in colon tumours and several cancer cell lines (Barker et al, 1997; Llor et al, 1999; Kamalati et al, 2000; Meric et al, 2002; Derry et al, 2003).

PTK6 possesses sequences with predicted homology with Src domains (SH3 and SH2) (Kamalati et al, 1996; Zhang et al, 2005), suggesting interactions with other signalling proteins. On account of the known involvement of Src in epithelial tumour development and structural similarities with Src, PTK6 is thought to have a function in epithelial tumorigenesis (Petro et al, 2004; Zhang et al, 2005).

*Correspondence: Dr M Aubele, Helmholtz Zentrum München, Institut für Pathologie, Ingolstädter Landstrasse I, Neuherberg 85764, Germany; E-mail: aubele@helmholtz-muenchen.de

Received 3 June 2008; revised 18 August 2008; accepted 18 August 2008; published online 9 September 2008
Several in vitro studies have attempted to identify the physiological function and the interaction partners of PTK6. Many of these suggest a possible involvement of PTK6 in modulating signal transduction of HER receptor tyrosine kinases (Kamalati et al, 1996, 2000; Chen et al, 2004; Haegebarth et al, 2005; Zhang et al, 2005). Knockdown of PTK6 decreases proliferation in breast cancer cell lines (Harvey and Crompton, 2003) and blocks activity of a GTPase, of ERK5 (extracellular signal-regulated kinase) and p38 mitogenactivated protein kinase (MAPK), but not Akt (Mitchell et al, 1994; Barker et al, 1997; Llor et al, 1999; Born et al, 2005; Ostrander et al, 2007). Furthermore, PTK6 phosphorylates STAT3 (signal transducer and activator of transcription 3; Liu et al, 2006) and STAT 5b, leading to increased STAT 5b transcriptional activity in several breast cancer cell lines (Weaver and Silva, 2007).

In recent years, several additional PTK6 substrates have been identified (Derry et al, 2000; Babic et al, 2004; Haegebarth et al, 2004, 2005). The first reported substrate of PTK6 phosphorylation was Sam68 (Src-associated in mitosis $68 \mathrm{kDa}$ ), and it was shown that PTK6 negatively regulates its RNA-binding activity (Derry et al, 2000). This may have an impact on the post-transcriptional regulation of gene expression. 
Besides these important in vitro findings, PTK6's function in vivo remains largely undefined. Very little is known about its physiological relevance in inducing phosphorylation events, in particular in tumour tissue. As mentioned above, there is increasing evidence that PTK6 is involved in EGF receptor signalling (Kamalati et al, 1996; Born et al, 2005; Zhang et al, 2005). If true, this is a most important finding, as the HER receptors - in particular HER2/neu - are of therapeutic and prognostic significance in breast cancer (Slamon, 1990; Meric et al, 2002; Hudelist et al, 2003; Witton et al, 2003; Abd El-Rehim et al, 2004; Bianchi et al, 2006). The HER2/neu antibody trastuzumab induces tumour regression in approximately $30-35 \%$ of patients with HER2-amplified metastatic breast cancer (Hsieh and Moasser, 2007), indicating that additional signalling molecules may influence the biological response to trastuzumab. Cytoplasmic tyrosine kinases, such as PTK6, containing SH2 and SH3 domains, are thought to modify receptor tyrosine kinase signalling (Petro et al, 2004; Zhang et al, 2005).

The data concerning PTK6 expression in tumour tissues are, so far, very limited. PTK6 was found to be localised in the nucleus and cytoplasm in normal oral epithelium, and it was found in perinuclear regions in poorly differentiated oral squamous carcinomas (Petro et al, 2004). In normal breast epithelium, PTK6 expression is low or undetectable, but it is elevated in many breast carcinomas (Petro et al, 2004; Zhang et al, 2005; Aubele et al, 2007), indicating that PTK6 overexpression may be related to carcinogenesis. In contrast, high levels of PTK6 are expressed in some differentiating epithelial tissues, such as normal gastrointestinal tract, skin (Llor et al, 1999; Haegebarth et al, 2004), and prostate (Derry et al, 2003). Moreover, PTK6 expression is associated with the degree of differentiation of breast tissue as indicated by oestrogen receptor (ER) expression (Zhao et al, 2003).

As recently reported by us, PTK6 protein expression has prognostic value in a small set of 105 breast carcinomas (Aubele et al, 2007), and correlates with the expression of HER receptors (Born et al, 2005; Aubele et al, 2007). We have extended the study to a total of 426 patients with a long-term follow-up. As PTK6 seems to be implicated in signalling pathways, we have expanded our immunohistochemical analysis of PTK6 to its nuclear substrate Sam68, the signalling molecules MAPK and P-MAPK, and the tumour suppressor protein PTEN.

\section{MATERIALS AND METHODS}

\section{Patients and tumour samples}

Immunohistochemical studies were performed on formalin-fixed, paraffin-embedded tissues from invasive breast carcinomas. The study comprises 426 patients with a detailed long-term follow-up, including those cases reported previously (Aubele et al, 2007). Two hundred forty-four of the tumours were lymph node negative, 182 were node positive, and the majority of the tumours in this study were $<2 \mathrm{~cm}$ in size $(n=234)$. The hormone receptor status was evaluated immunohistochemically. Classification into negative (no or low) and positive (medium or high staining intensity) revealed that 311 and 141 tumours were ER positive and progesterone receptor (PrR) positive, respectively. Histological classification (WHO 2003) defined 332 tumours as being invasive ductal not otherwise specified (NOS). The remaining cases were classified as tubular (14), lobular (47), medullary (2), and others (31). A total of 221 cases were classified as grade 2, 109 cases as grade 3, and 96 cases as grade 1, according to Elston and Ellis (1991).

All patients were surgically treated, and none of the patients received preoperative treatment. Fifty patients received no postoperative treatment, whereas adjuvant antihormonal treatment was administered to 203 patients, radio- and/or chemotherapy to
33 patients, and 140 patients received combined treatment regimes (radio- and/or chemo- and/or antihormonal treatment).

The median clinical follow-up of patients was 80 months (mean 94, maximum 264 months) with $121(28 \%)$ of the patients relapsing with distant metastases and/or local recurrence within the total follow-up period. Ethical approval for the study was obtained from the Ethics Committee of the medical faculty of the Technical University of Munich.

\section{Tissue microarrays (TMA)}

Tissue microarray construction was performed using the same quality criteria and methodology as described with a tissuearraying instrument (Beecher Instruments Inc., Silver Spring, MD, USA) (Aubele et al, 2007). $5 \mu \mathrm{m}$ sections were cut from the TMA blocks, and both the TMA and punched block were re-examined to validate representative sampling.

\section{Immunohistochemistry (IHC)}

For IHC on the TMA sections, the antibodies for HER1, HER2/neu, HER3, HER4, and PTK6 were used as described previously (Aubele et al, 2007). For further immunohistochemical analysis the following antibodies were applied (Table 1): p44/42 MAP kinase (Erk1 and Erk2), P-MAPK (detecting p44/42 MAPK phosphorylated on Thr202/Tyr204), PTEN (phosphatase and tensin homologue deleted on chromosome 10), and Sam68. Deparaffinisation of the TMA sections, antigen retrieval, and incubation with the primary antibody were performed as described (QuintanillaMartinez et al, 2003). Staining and counterstaining were performed by an automated immunostainer (Ventana Medical System, Tucson, AZ, USA) (Quintanilla-Martinez et al, 2003; Aubele et al, 2007).

Tissue staining intensities were scored by two independent observers as described (Witton et al, 2003; Aubele et al, 2007) using a 4 -point scale, where $0=$ no staining, $1=$ light staining, $2=$ moderate staining, and $3=$ strong staining. Immunohistochemical positivity for Sam68 was scored in percent positive stained tumor cells.

\section{Cell culture}

T47D cells were obtained from the American Type Culture Collection and maintained in RPMI (Roswell Park Memorial Institute medium) supplemented with $10 \%$ foetal bovine serum (FBS), bovine insulin $\left(10 \mu \mathrm{g} \mathrm{ml}^{-1}\right)$, and the antibiotics penicillin and streptomycin $(0.25 \%)$ at $37^{\circ} \mathrm{C}$ in $5 \% \mathrm{CO}_{2}$.

\section{Protein isolation, immunoprecipitation (IP), and western blot}

For physical disruption of the cells, the T47D cell suspension was sonicated using high-frequency sound waves $(3 \times 30 \mathrm{~s}$, power $30 \%)$. For protein isolation, the T-PER ${ }^{\circledR}$ Tissue Protein Extraction Reagent (Pierce, Rockford, IL, USA) was supplemented with Complete Mini-Protease inhibitor cocktail tablets (Roche, Mannheim, Germany), Phosphatase Inhibitor cocktail $1+2$ (Sigma-Aldrich, Hamburg, Germany), and the extraction was performed according to the manufacturer's protocol.

For IP, the Seize ${ }^{\circledR}$ Primary Immunoprecipitation Kit (Pierce, Rockford, IL, USA) was applied according to the manufacturer's protocol with slight modifications. The primary antibody, PTK6, was coupled to AminoLink ${ }^{\circledR}$ Plus Coupling Gel at $22^{\circ} \mathrm{C}$ for $4 \mathrm{~h}$ with gentle end-over-end mixing. The antigen (protein lysate, $500 \mu \mathrm{g}$ ) was precipitated at $22^{\circ} \mathrm{C}$ for $1.5 \mathrm{~h}$ with gentle end-over-end mixing. The precipitates were eluted using the ImmunoPure ${ }^{\circledR}$ elution buffer, containing $1 \%$ SDS to achieve dissociation of the antigen from the covalently immobilised antibody. The eluates were 
Table I Sources and dilutions of antibodies used for $\mathrm{IHC}$ and western blotting, respectively

\begin{tabular}{|c|c|c|c|}
\hline \multirow[b]{2}{*}{ Antibodies } & \multirow[b]{2}{*}{ Source } & \multicolumn{2}{|c|}{ Dilution } \\
\hline & & IHC & WB \\
\hline PTK6 (BRK; mouse) & 5GI (sc-66003), Santa Cruz Biotechnology, Heidelberg, Germany & & $1: 200$ \\
\hline HERI (EGF-R; mouse) & 3। G7, Invitrogen, Heidelberg, Germany & $1: 50$ & \\
\hline HERI (EGF-R; rabbit) & H7298, DAKO, Glostrup, Denmark & & $1: 50$ \\
\hline HER2/neu (ErbB2; rabbit) & Hercep test ${ }^{\mathrm{TM}}$, K5204, DAKO, Hamburg, Germany & Ready for use & \\
\hline HER3 (erbB3; mouse) & 20IP506A, Lab Vision Corp. Fremont, CA, USA & & I:5000 \\
\hline HER4 (erbB4; mouse) & H4.77.16, Stratech, Suffolk, England & $1: 20$ & \\
\hline HER4 (erbB4; rabbit) & 4795, Cell Signaling Technology, Beverly, MA, USA & & $1: 500$ \\
\hline p44/42 MAP kinase (Erkl and Erk2; rabbit) & 4695, Cell Signaling Technology, Beverly, MA, USA & $1: 100$ & $1: 10000$ \\
\hline p44/42 MAP kinase (rabbit) & 9102, Cell Signaling Technology, Beverly, MA, USA & & I:5000 \\
\hline Phosphorylated MAPK (rabbit) & 9I0I, Cell Signaling Technology, Beverly, MA, USA & $1: 100$ & \\
\hline Phosphorylated MAPK (rabbit) & 4376, Cell Signaling Technology, Beverly, MA, USA & & $1: 5000$ \\
\hline
\end{tabular}

$\mathrm{IHC}=$ immunohistochemistry.

analysed by western blotting, using a standard concentration of $1: 1000$ of the primary antibody. To confirm the interaction of PTK6 and MAPK, an inverse IP with the immobilised MAPKtargeted antibody was carried out, and precipitated PTK6 was detected by western blot. To show that the interactions are due to a specific binding with PTK6, and not to an adsorption to beads, IP without antibody was also performed.

For western blot analysis, $20 \mu \mathrm{g}$ samples of protein lysate were resolved by SDS - polyacrylamide gel electrophoresis, and transferred to nitrocellulose membranes (Schleicher and Schuell, Dassel, Germany). Proteins were then detected with antibodies against PTK6, Sam68, HER2/neu, HER3, HER4, PTEN, MAPK, and phosphorylated MAPK (Table 1). The appropriate peroxidaseconjugated secondary antibodies (antirabbit NA934V, antimouse NA931V, 1:2000) were obtained from the GE Healthcare (Munich, Germany).

\section{Statistics}

Correlations among the immunohistochemically evaluated markers, and between markers and clinical parameters, were examined by Spearman's rank correlation test. HER1 positivity was infrequent (only $6 \%$ of the cases), and was excluded from statistical analysis. Survival analysis was performed using disease-free interval for follow-up periods of 60,120 , and 240 months. The disease-free interval was defined as the interval from the date of surgery to the first locoregional recurrence and/or distant metastases.

For univariate survival analysis, Kaplan-Meier curves were calculated, and differences between strata were tested with the log-rank $\chi^{2}$-value. The multivariate analysis was performed using Cox proportional hazards regression and a combined stepwise selection algorithm (SAS Institute, Cary, NC, USA). All parameters reaching a significance level of $P \leqslant 0.15$ in univariate analysis were offered to multivariate analysis. In all other tests, statistical significance was considered proven if $P \leqslant 0.05$.

\section{RESULTS}

PTK6 expression, its cooverexpression, and its correlation with other parameters

Two-thirds $(69 \%, n=293)$ of the breast carcinomas showed a high PTK6 expression (IHC 2+, 3+; Table 2). In decreasing order, we
Table 2 Frequency of tumours (\%) showing overexpression of markers, and co-overexpression between PTK6 and the other markers ${ }^{\mathrm{a}}$

\begin{tabular}{lcc}
\hline & $\begin{array}{c}\text { Highly } \\
\text { expressed (\%) }\end{array}$ & $\begin{array}{c}\text { Co-overexpressed } \\
\text { with PTK6 } \\
\text { (\% of highly expressed) }\end{array}$ \\
\hline PTK6 & 68.9 & \\
PTEN & 28.4 & 77.4 \\
Sam68 & 52.1 & 73.9 \\
MAPK & 33.7 & 70.3 \\
P-MAPK & 6.5 & 94.4 \\
\hline
\end{tabular}

$\mathrm{HC}=$ immunohistochemistry; $\mathrm{MAPK}=$ mitogen-activated protein kinase; Sam68 =

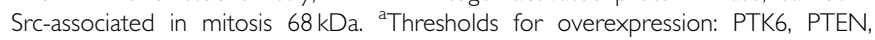
MAKP, and P-MAPK; IHC $\geqslant 2+$; Sam68 IHC: $\geqslant 50 \%$ positive tumour cells.

found the overexpression of Sam68 (52\%), MAPK (34\%), PTEN (28\%), and P-MAPK (in $7 \%$ of tumours). Most of these overexpressing tumours show co-overexpression with PTK6, as shown in (Table 2). The expression of PTK6 was not significantly correlated with clinical and histopathological parameters, such as lymph node status, tumour size, and histological grade or type (Table 3). Further, no association was found between PTK6 and HER2, HER3, and HER4 receptor expression. A significant correlation was observed between the expression of PTK6 and the expression of PTEN $(P=0.002)$, Sam68 $(P=0.0008)$, MAPK $(P=0.01)$, and phosphorylated MAPK $(P=0.001$; Table 4$)$.

\section{Prognostic relevance of parameters}

Univariate analysis of parameters for a disease-free survival of patients All clinical, histopathological, and immunohistochemical parameters were analysed for their prognostic relevance using Kaplan-Meier analysis. A significant inverse correlation with the disease-free survival of patients was found for lymph node status $(P \leqslant 0.0001)$, tumour size $(P \leqslant 0.0001)$, and the histological grade of tumours $(P=0.002)$. A direct correlation $(P \leqslant 0.02)$ with the disease-free survival of patients was identified for PgR positivity and expression of HER4, PTK6, and Sam68 (Table 5). No significant survival effect was observed in univariate analysis for HER2/neu (0.08), HER3 (0.3), PTEN (0.2), MAPK (0.98), and P-MAPK (0.7), or for the ER status (0.2; Table 5).

Multivariate analysis Multivariate analysis was used to assess the influence of markers on the disease-free survival of patients, 
Table 3 Correlations between immunohistochemically assessed protein expressions and the clinicohistopathological parameters

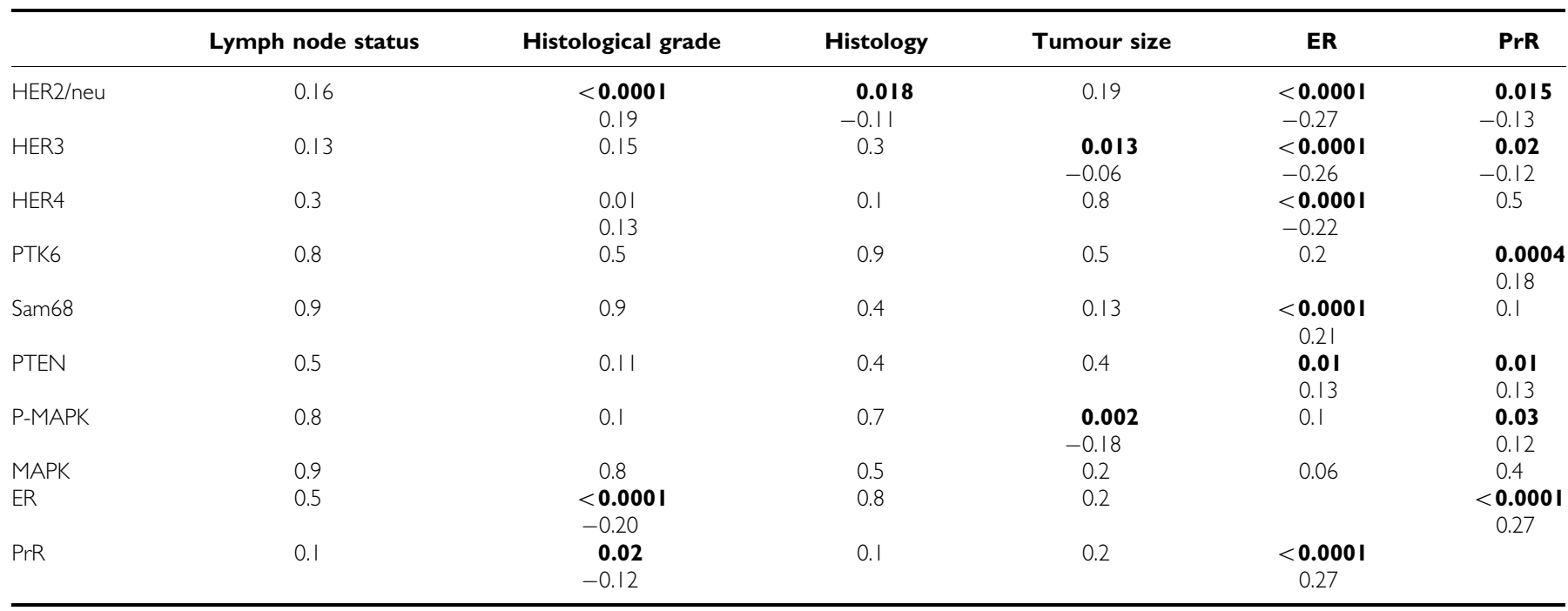

$E R=$ oestrogen receptor $; \mathrm{MAPK}=$ mitogen-activated protein kinase; PrR = progesterone receptor; Sam68 = Src-associated in mitosis 68 kDa. For significant correlations, the $P$-values are printed in bold, and the rho factors are given. Negative rho factors = inverse correlation.

Table 4 Correlations between immunohistochemically assessed markers

\begin{tabular}{|c|c|c|c|c|c|c|c|c|c|}
\hline & HER2/neu & HER3 & HER4 & PTK6 & PTEN & Sam68 & MAPK & P-MAPK & ER \\
\hline PTK6 & 0.17 & 0.8 & 0.3 & & & & & & \\
\hline PTEN & 0.5 & 0.1 & 0.4 & $\begin{array}{l}\mathbf{0 . 0 0 1 6} \\
0.17\end{array}$ & & & & & \\
\hline MAPK & 0.15 & $\begin{array}{l}\mathbf{0 . 0 0 1 8} \\
0.21\end{array}$ & $\begin{array}{c}<\mathbf{0 . 0 0 0} \mathbf{I} \\
0.30\end{array}$ & $\begin{array}{l}\mathbf{0 . 0 1} \\
0.15\end{array}$ & $\begin{array}{l}\mathbf{0 . 0 1 1} \\
0.16\end{array}$ & $\begin{array}{l}\mathbf{0 . 0 3 3} \\
0.13\end{array}$ & & & \\
\hline P-MAPK & 0.23 & $\begin{array}{l}0.018 \\
0.17\end{array}$ & $\begin{array}{c}<\mathbf{0 . 0 0 0} \mathbf{I} \\
0.26\end{array}$ & $\begin{array}{l}\mathbf{0 . 0 0 1} \\
0.16\end{array}$ & 0.2 & 0.1 & & & \\
\hline ER & $\begin{array}{l}<\mathbf{0 . 0 0 0 1} \\
-0.26\end{array}$ & $\begin{array}{l}<\mathbf{0 . 0 0 0 1} \\
-0.27\end{array}$ & $\begin{array}{l}<\mathbf{0 . 0 0 0 1} \\
-0.22\end{array}$ & 0.23 & $\begin{array}{l}\mathbf{0 . 0 1} \\
0.13\end{array}$ & $\begin{array}{c}<\mathbf{0 . 0 0 0 1} \\
0.21\end{array}$ & 0.06 & 0.14 & \\
\hline PrR & $\begin{array}{l}\mathbf{0 . 0 1 5} \\
-0.12\end{array}$ & $\begin{array}{r}\mathbf{0 . 0 2} \\
-0.13\end{array}$ & 0.5 & $\begin{array}{l}\mathbf{0 . 0 0 0 4} \\
0.18\end{array}$ & $\begin{array}{l}\mathbf{0 . 0 1 4} \\
0.13\end{array}$ & 0.11 & 0.37 & $\begin{array}{l}\mathbf{0 . 0 3 2} \\
0.12\end{array}$ & $\begin{array}{c}<\mathbf{0 . 0 0 0} \mathbf{I} \\
0.27\end{array}$ \\
\hline
\end{tabular}

MAPK = mitogen-activated protein kinase; $\mathrm{PrR}=$ progesterone receptor; Sam68 = Src-associated in mitosis $68 \mathrm{kDa}$. For significant correlations, the $P$-values are printed in bold, and the rho factors are given. Negative rho factors = inverse correlation.

Table 5 Results from univariate analysis of the single parameters for a disease-free survival of patients of $\geqslant 240$ months

\begin{tabular}{ll}
\hline Parameter & $\mathbf{P}$-value \\
\hline Lymph node status $(+/-)$ & $\mathbf{P} \leqslant \mathbf{0 . 0 0 0 1}$ \\
Tumour size $(\leqslant 20,20-40,>40 \mathrm{~mm})$ & $\mathbf{P} \leqslant \mathbf{0 . 0 0 0} \mathbf{I}$ \\
Histological grade & $\mathbf{P}=\mathbf{0 . 0 0 2}$ \\
Progesterone receptor & $\mathbf{P}=\mathbf{0 . 0 2}^{\mathbf{a}}$ \\
Oestrogen receptor & $P=0.15$ \\
HER2/neu & $P=0.08$ \\
HER3 & $P=0.25$ \\
HER4 & $\mathbf{P}=\mathbf{0 . 0 2 8}^{\mathbf{a}}$ \\
PTK6 & $\mathbf{P}=\mathbf{0 . 0 0 \mathbf { I } ^ { \mathbf { a } }}$ \\
Sam68 & $\mathbf{P}=\mathbf{0 . 0 1 \mathbf { 8 } ^ { \mathbf { a } }}$ \\
MAPK & $P=0.98$ \\
P-MAPK & $P=0.7$ \\
PTEN & $P=0.18$ \\
\hline
\end{tabular}

MAPK $=$ mitogen-activated protein kinase. Significant $P$-values are printed in bold. aHigh expression corresponds to better prognosis. together with that of the clinicohistopathological parameters. The stepwise selected parameters for a disease-free survival of patients of $>240$ months were lymph node status (risk factor 2.1), PTK6 expression (0.6), and tumour size (1.6; Table 6).

The prognostic value of key markers appeared to be time dependent (Aubele et al, 2007). Performing multivariate analysis for an interval of 60 months, the tumour size (risk factor 1.9), PTK6 expression (0.6), HER2/neu (1.0), and lymph node status (1.7) were independently prognostic. At an interval of 120 months, HER2/neu protein expression was no longer significant. Here, the stepwise selected parameters were lymph node status (risk factor 2.1), PTK6 expression (0.6), and tumour size (1.5).

The cohorts studied Comparing the primary and the expanded tumour cohort with histopathological parameters showed that both cohorts contain different portions of ER- and PrR-positive tumours. Whereas the primary cohort contains 39\% ER- and 33\% PrR-positive tumours, the expanded cohort contains $79 \%$ ER- and $32 \%$ PrR-positive tumours. No prominent differences between the 
cohorts were found in relation to the lymph node status, tumour size, and the histological grade.

Performing multivariate analyses only with the newly added cases, the stepwise selected parameters for a disease-free survival of patients of $>240$ months were lymph node status (risk factor 2.3), tumour size (1.6), and PTK6 expression (0.7). This result is entirely in accordance with the results from the primary and the expanded cohort.

\section{Proteins coprecipitating with PTK6}

To analyse whether significant correlations among the expression level of different protein markers in tumour tissue are based on possible complex formation between these proteins, we performed IP with the PTK6 antibody using the T47D breast cancer cell line.

Table 6 Results of the Cox multivariate regression analysis

\begin{tabular}{|c|c|c|c|}
\hline Parameter & $P$-value & Coefficient & $\begin{array}{l}\text { Relative } \\
\text { risk }\end{array}$ \\
\hline \multicolumn{4}{|l|}{ Total interval (>240 months): } \\
\hline Lymph node status (+/-) & 0.0003 & 0.85 & 2.34 \\
\hline PTK6 expression & 0.0058 & -0.42 & $0.66^{\mathrm{a}}$ \\
\hline \multirow{2}{*}{$\begin{array}{l}\text { Tumour size } \\
(-10,10-20,>20 \mathrm{~mm})\end{array}$} & 0.01 & 0.41 & 1.52 \\
\hline & & & Total $P \leqslant 0.0001$ \\
\hline \multicolumn{4}{|l|}{ Interval, 120 months: } \\
\hline Lymph node status (+/-) & 0.0004 & 0.84 & 2.32 \\
\hline PTK6 expression & 0.011 & -0.40 & $0.67^{\mathrm{a}}$ \\
\hline \multirow{2}{*}{$\begin{array}{l}\text { Tumour size } \\
(-10,10-20,>20 \mathrm{~mm})\end{array}$} & 0.013 & 0.41 & 1.50 \\
\hline & & & Total $P<0.0001$ \\
\hline \multicolumn{4}{|l|}{ Interval, 60 months: } \\
\hline $\begin{array}{l}\text { Tumour size } \\
(-10,10-20,>20 \mathrm{~mm})\end{array}$ & 0.0013 & 0.61 & 1.84 \\
\hline Lymph node status (+/-) & 0.011 & 0.75 & 2.11 \\
\hline HER2/neu expression & 0.024 & 0.0035 & 1.004 \\
\hline PTK6 expression & 0.045 & -0.384 & Total $P<0.0001^{0.681^{\mathrm{a}}}$ \\
\hline
\end{tabular}

The summary of stepwise selected parameters is given for a disease-free survival of $>240$ months, 120 months, and 60 months. Positive coefficients increase and negative coefficients reduce the risk of an event. "High expression corresponds to better prognosis.
Subsequent western blot analysis showed that PTK6 coprecipitated with MAPK, P-MAPK, HER2/neu, HER3, HER4, Sam68, and PTEN in T47D cell line (Figure 1). These results suggest that the correlations of IHC staining intensities in tumour tissues may represent molecular interactions between the corresponding proteins, as shown in T47D cell line.

\section{DISCUSSION}

In this study, we investigated protein expression of the cytoplasmic protein kinase PTK6 (BRK), the HER receptors, Sam68, PTEN, MAPK, and P-MAPK in breast carcinomas, and tested the associations between these markers and patient prognosis. We show that PTK6 protein expression is a prognostic marker for disease-free survival, on the basis of the data from a cohort of 426 invasive breast cancer cases. Further, we confirm the time dependence of the different prognostic parameters. The prognostic significance of HER receptors was only evident for short time period (60 months), as published previously, on the basis of the data from 105 breast carcinomas (Aubele et al, 2007). A similar time dependence of prognostic markers has also been reported by Tovey et al (2005) for the progesterone and HER1 - HER3 receptor expression in breast cancer.

The expression of PTK6 in breast carcinoma tissue was not associated with clinicohistopathological parameters, confirming our previous results (Aubele et al, 2007). In another study, however, PTK6 staining intensities were found to correlate with the histological grade of 250 breast carcinomas (Ostrander et al, 2007). Those discrepant findings may be caused by different compositions of the tumour cohorts.

A significant correlation between the protein expressions of PTK6 and HER2/neu, HER3, and HER4 was recently published (Aubele et al, 2007). The small cohort of tumour cases $(n=105)$ used previously was now expanded to include 426 invasive breast carcinoma cases. The results presented here could not confirm a previously found significant correlation between PTK6 and HER receptor expression. This discrepancy in the results may also be due to differences in the composition of the cohorts. The cohort studied here contains proportionally more hormone-receptorpositive tumours. This may influence and change the statistical results, and is further supported by the novel finding that PTK6 expression correlates directly with the PrR status, which was not the case in our previous study.

The comparison of protein expression between the markers in tumour tissue showed that Sam68, PTEN, MAPK, and P-MAPK are
A

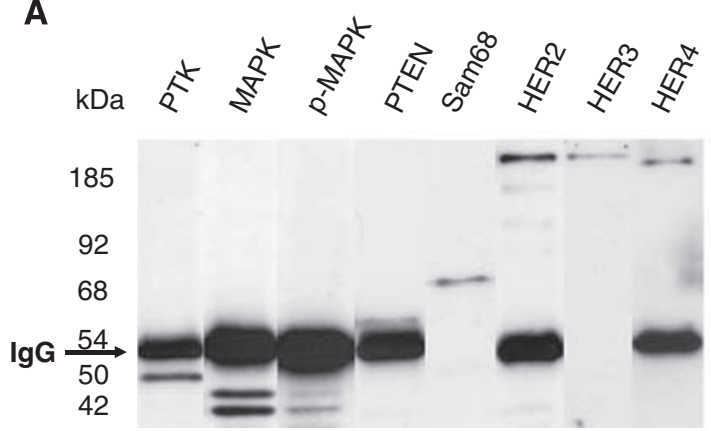

B $\mathrm{kDa}$
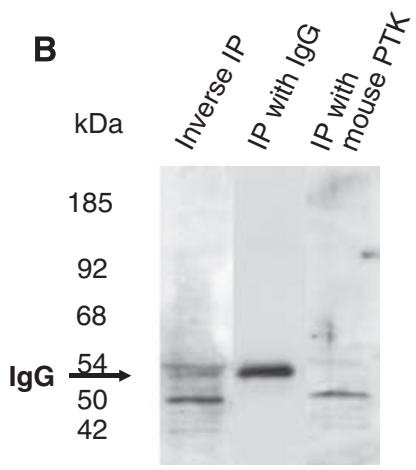

Figure I PTK6 coprecipitates with several signalling molecules in human breast cancer cell line, T47D (The specifity of single bands was proven using total cell lysates and western blot). (A) IP using the (rabbit) PTK6 antibody was analysed by western blot with rabbit antibodies specific for PTK, MAPK, P-MAPK, PTEN, HER2, and HER4, and mouse antibodies specific for Sam68 and HER3. (B) Inverse IP using rabbit antibody specific for MAPK was analysed by western blot with rabbit antibody specific for PTK6. IPs using rabbit IgG (sc-2027, Santa Cruz Biotechnology) and mouse PTK6 antibodies were analysed by western blot with the rabbit PTK6 antibody. No signals were detected by western blot after IP with the rabbit PTK6 antibody, which was blocked by PTK6 peptide (sc-I I 88P, Santa Cruz Biotechnology). 
all significantly correlated with PTK6 expression. To get an indication whether these statistical correlations of markers in tumour tissue may be caused by molecular associations with PTK6, we used IP and found that Sam68, PTEN, MAPK, and P-MAPK all coprecipitate with PTK6. Sam68 was originally identified as one of the major targets for PTK6 (Taylor and Shalloway, 1994; Derry et al, 2000; Babic et al, 2004; Haegebarth et al, 2004, 2005). It has been demonstrated that Sam68 is a substrate downstream of the EGFR (Lukong et al, 2005), and that tyrosine phosphorylation of Sam68 by PTK6 regulates negatively its RNA-binding activity (Derry et al, 2000; Babic et al, 2004; Haegebarth et al, 2004; Lukong et al, 2005). In our study, Sam68 expression was significantly associated with PTK6 and with PTEN expression, and inversely correlated with the expression of HER3 and HER4. Further, a direct correlation was identified between Sam68 expression and the disease-free survival of patients in univariate analysis.

PTEN was selected for our immunohistochemical study, because loss of PTEN expression showed correlation with disease-related death, lymph node metastasis (Depowski et al, 2001), and development of distant metastases in 88 tumour samples (Piekarski and Biernat, 2006). Positive PTEN expression in breast cancer tissue was associated with low tumour grade, longer survival time, and ER positivity (Winter et al, 2007). In our study, PTEN expression was correlated with the expression of PTK6 and with PrR and ER, confirming the results from Winter et al (2007). The association between PTK6 and PTEN expression in tissue corresponds to the coprecipitation of these proteins in the T47D cell line, indicative for a molecular association or complex formation of markers. The physiological meaning of this association must be analysed in more detail in future in vitro studies. No association could be identified between PTEN and the patients' prognosis, lymph node status, or tumour size.

Mitogen-activated protein kinase is known to be activated by HER receptors and to promote proliferation. Knockdown of PTK6-reduced proliferation (Harvey and Crompton, 2003) and Heregulin- and EGF-induced activation of Rac GTPase, ERK5, and MAPK (Ostrander et al, 2007). Gutierrez et al (2005)reported that high levels of active phosphorylated MAPK (p38MAPK) strongly correlated with upregulated HER2 and increased tamoxifen resistance in clinical specimens. In our study, we found a significant correlation between P-MAPK expression and the expression of PTK6, HER3, and HER4, but not with HER2. We further found a correlation between PTK6 expression and the levels of MAPK and P-MAPK in tumour tissues. A significant association, however, was found for PTK6, but not for MAPK or P-MAPK with patients' disease-free survival.

\section{REFERENCES}

Abd El-Rehim DM, Pinder SE, Paish CE, Bell JA, Rampaul RS, Blamey RW, Robertson JF, Nicholson RI, Ellis IO (2004) Expression and coexpression of the members of the epidermal growth factor receptor (EGFR) family in invasive breast carcinoma. Br J Cancer 91: 1532 - 1542

Aubele M, Auer G, Walch AK, Munro A, Atkinson MJ, Braselmann H, Fornander T, Bartlett JM (2007) PTK (protein tyrosine kinase)-6 and HER 2 and 4, but not HER1 and 3 predict long-term survival in breast carcinomas. Br J Cancer 96: 801 - 807

Babic I, Jakymiw A, Fujita DJ (2004) The RNA binding protein Sam68 is acetylated in tumor cell lines, and its acetylation correlates with enhanced RNA binding activity. Oncogene 23: 3781-3789

Barker KT, Jackson LE, Crompton MR (1997) BRK tyrosine kinase expression in a high proportion of human breast carcinomas. Oncogene 15: $799-805$

Bianchi S, Palli D, Falchetti M, Saieva C, Masala G, Mancini B, Lupi R, Noviello C, Omerovic J, Paglierani M, Vezzosi V, Alimandi M, Mariani-Costantini R, Ottini L (2006) ErbB-receptors expression and survival in breast carcinoma: a 15-year follow-up study. J Cell Physiol 206: $702-708$
Although several interaction partners of PTK6 have been identified in cellular cultures, the signalling function of PTK6 as well as its function in breast cancer development and prognosis remains unclear. It is well accepted that the HER receptors transduce signals through associations with a variety of cytoplasmic target proteins containing SH2 and/or SH3 domains. PTK6 possesses both SH2 and SH3 domains (Kamalati et al, 1996; Zhang et al, 2005), and there is every reason to believe that it participates in HER receptor signalling processes. According to the current state of knowledge, however, association partners of PTK6 have been identified from all three main signal transduction pathways. It interacts and negatively regulates Akt (Kamalati et al, 2000; Zhang et al, 2005; Haegebarth et al, 2006). In addition, here, we could show that also PTEN, which belongs to the same PI3K/Akt signalling pathway, coprecipitates with PTK6 in T47D cell line, and is statistically associated with the expression of PTK6 in tumour tissue. PTK6 influences the MAPK pathway (as described above), and there is evidence that STATs are also physiological targets of PTK6 (Liu et al, 2006; Weaver and Silva, 2007). This obvious involvement of PTK6 in all three signalling pathways may be explained to some extent by cross talk between pathways. Moreover, PTK6 may function in post-transcriptional regulation of gene expression and through modulating the utilisation of messenger RNAs (Harvey and Crompton, 2004), thus influencing post-transcriptional activity of many other proteins. Therefore, elevated PTK6 expression in tumour tissue is presumably accompanied by alterations to the expression levels of multiple other molecules.

In conclusion, in this study, we show that PTK6 protein expression in 426 breast cancer cases is of high prognostic value, independent of the classical morphological and molecular markers, such as lymph node involvement, tumour size, and HER2 status. Although the role of PTK6 in breast cancer development and prognosis is not known, these results are of important clinical relevance as PTK6 may be a potential future target for the development of novel treatments for breast cancer. On the basis of this data and other expression studies, there is compelling reason to further investigate the cellular function and interaction pathways of PTK6.

\section{ACKNOWLEDGEMENTS}

This study was partly supported by the Deutsche Krebshilfe, contract 10379, and by the European Commisson, 'TRANSBIG'Project, no. LSHC-CT-2004-503426. Ethical approval for this study was obtained from the Ethics Committee of the Medical Faculty of the Technical University of Munich.
Born M, Quintanilla-Fend L, Braselmann H, Reich U, Richter M, Hutzler P, Aubele M (2005) Simultaneous over-expression of the Her2/neu and PTK6 tyrosine kinases in archival invasive ductal breast carcinomas. J Pathol 205: 592-596

Chen HY, Shen CH, Tsai YT, Lin FC, Huang YP, Chen RH (2004) Brk activates racl and promotes cell migration and invasion by phosphorylating paxillin. Mol Cell Biol 24: $10558-10572$

Depowski PL, Rosenthal SI, Ross JS (2001) Loss of expression of the PTEN gene protein product is associated with poor outcome in breast cancer. Mod Pathol 14: 672-676

Derry JJ, Prins GS, Ray V, Tyner AL (2003) Altered localization and activity of the intracellular tyrosine kinase BRK/Sik in prostate tumor cells. Oncogene 22: 4212 - 4220

Derry JJ, Richard S, Valderrama Carvajal H, Ye X, Vasioukhin V, Cochrane AW, Chen T, Tyner AL (2000) Sik (BRK) phosphorylates Sam68 in the nucleus and negatively regulates its RNA binding ability. Mol Cell Biol 20: 6114-6126

Elston CW, Ellis IO (1991) Pathological prognostic factors in breast cancer. I. The value of histological grade in breast cancer: experience 
from a large study with long-term follow-up. Histopathology 19: $403-410$

Gutierrez MC, Detre S, Johnston S, Mohsin SK, Shou J, Allred DC, Schiff R, Osborne CK, Dowsett M (2005) Molecular changes in tamoxifen-resistant breast cancer: relationship between estrogen receptor, HER-2, and p38 mitogen-activated protein kinase. J Clin Oncol 23: 2469-2476

Haegebarth A, Bie W, Yang R, Crawford SE, Vasioukhin V, Fuchs E, Tyner AL (2006) Protein tyrosine kinase 6 negatively regulates growth and promotes enterocyte differentiation in the small intestine. Mol Cell Biol 26: 4949 - 4957

Haegebarth A, Heap D, Bie W, Derry JJ, Richard S, Tyner AL (2004) The nuclear tyrosine kinase BRK/Sik phosphorylates and inhibits the RNA-binding activities of the Sam68-like mammalian proteins SLM-1 and SLM-2. J Biol Chem 279: 54398-54404

Haegebarth A, Nunez R, Tyner AL (2005) The intracellular tyrosine kinase Brk sensitizes non-transformed cells to inducers of apoptosis. Cell Cycle 4: $1239-1246$

Harvey AJ, Crompton MR (2003) Use of RNA interference to validate Brk as a novel therapeutic target in breast cancer: Brk promotes breast carcinoma cell proliferation. Oncogene 22: 5006-5010

Harvey AJ, Crompton MR (2004) The Brk protein tyrosine kinase as a therapeutic target in cancer: opportunities and challenges. Anticancer Drugs 15: 107 - 111

Hsieh AC, Moasser MM (2007) Targeting HER proteins in cancer therapy and the role of the non-target HER3. Br J Cancer 97: 453-457

Hudelist G, Singer CF, Manavi M, Pischinger K, Kubista E, Czerwenka K (2003) Co-expression of ErbB-family members in human breast cancer: Her-2/neu is the preferred dimerization candidate in nodal-positive tumors. Breast Cancer Res Treat 80: $353-361$

Kamalati T, Jolin HE, Fry MJ, Crompton MR (2000) Expression of the BRK tyrosine kinase in mammary epithelial cells enhances the coupling of EGF signalling to PI 3-kinase and Akt, via erbB3 phosphorylation. Oncogene 19: 5471 - 5476

Kamalati T, Jolin HE, Mitchell PJ, Barker KT, Jackson LE, Dean CJ, Page MJ, Gusterson BA, Crompton MR (1996) Brk, a breast tumor-derived non-receptor protein-tyrosine kinase, sensitizes mammary epithelial cells to epidermal growth factor. J Biol Chem 271: 30956-30963

Liu L, Gao Y, Qiu H, Miller WT, Poli V, Reich NC (2006) Identification of STAT3 as a specific substrate of breast tumor kinase. Oncogene 25: 4904-4912

Llor X, Serfas MS, Bie W, Vasioukhin V, Polonskaia M, Derry J, Abbott CM, Tyner AL (1999) BRK/Sik expression in the gastrointestinal tract and in colon tumors. Clin Cancer Res 5: $1767-1777$

Lukong KE, Larocque D, Tyner AL, Richard S (2005) Tyrosine phosphorylation of sam 68 by breast tumor kinase regulates intra- nuclear localization and cell cycle progression. I Biol Chem 280: $38639-38647$

Meric F, Lee WP, Sahin A, Zhang H, Kung HJ, Hung MC (2002) Expression profile of tyrosine kinases in breast cancer. Clin Cancer Res 8: $361-367$

Mitchell PJ, Barker KT, Martindale JE, Kamalati T, Lowe PN, Page MJ, Gusterson BA, Crompton MR (1994) Cloning and characterisation of cDNAs encoding a novel non-receptor tyrosine kinase, brk, expressed in human breast tumours. Oncogene 9: 2383-2390

Ostrander JH, Daniel AR, Lofgren K, Kleer CG, Lange CA (2007) Breast tumor kinase (protein tyrosine kinase 6) regulates heregulin-induced activation of ERK5 and p38 MAP kinases in breast cancer cells. Cancer Res 67: 4199-4209

Petro BJ, Tan RC, Tyner AL, Lingen MW, Watanabe K (2004) Differential expression of the non-receptor tyrosine kinase BRK in oral squamous cell carcinoma and normal oral epithelium. Oral Oncol 40: 1040-1047

Piekarski JH, Biernat W (2006) Clinical significance of CK5/6 and PTEN protein expression in patients with bilateral breast carcinoma. Histopathology 49: $248-255$

Quintanilla-Martinez L, Davies-Hill T, Fend F, Calzada-Wack J, Sorbara L, Campo E, Jaffe ES, Raffeld M (2003) Sequestration of p27Kip1 protein by cyclin D1 in typical and blastic variants of mantle cell lymphoma (MCL): implications for pathogenesis. Blood 101: $3181-3187$

Slamon DJ (1990) Studies of the HER-2/neu proto-oncogene in human breast cancer. Cancer Invest 8: 253

Taylor SJ, Shalloway D (1994) An RNA-binding protein associated with Src through its SH2 and SH3 domains in mitosis. Nature 368: 867-871

Tovey S, Dunne B, Witton CJ, Forsyth A, Cooke TG, Bartlett JM (2005) Can molecular markers predict when to implement treatment with aromatase inhibitors in invasive breast cancer? Clin Cancer Res 11: 4835-4842

Weaver AM, Silva CM (2007) Signal transducer and activator of transcription 5b: a new target of breast tumor kinase/protein tyrosine kinase 6. Breast Cancer Res 9: R79

Winter JL, Stackhouse BL, Russell GB, Kute TE (2007) Measurement of PTEN expression using tissue microarrays to determine a race-specific prognostic marker in breast cancer. Arch Pathol Lab Med 131: $767-772$

Witton CJ, Reeves JR, Going JJ, Cooke TG, Bartlett JM (2003) Expression of the HER1-4 family of receptor tyrosine kinases in breast cancer. J Pathol 200: $290-297$

Zhang P, Ostrander JH, Faivre EJ, Olsen A, Fitzsimmons D, Lange CA (2005) Regulated association of protein kinase B/Akt with breast tumor kinase. J Biol Chem 280: $1982-1991$

Zhao C, Yasui K, Lee CJ, Kurioka H, Hosokawa Y, Oka T, Inazawa J (2003) Elevated expression levels of NCOA3, TOP1, and TFAP2C in breast tumors as predictors of poor prognosis. Cancer 98: 18-23 